\title{
A Psicologia Brasileira e os Povos Indígenas: Atualização do Estado da Arte
}

\author{
Isabella Tormena Ferraz \\ Universidade Estadual de Maringá, PR, Brasil.
}

\author{
Eliane Domingues \\ Universidade Estadual de Maringá, PR, Brasil.
}

\begin{abstract}
Resumo: De acordo com o último censo do IBGE (2010a), 0,4\% da população brasileira é composta por indígenas, população que vem aumentando nos últimos anos e cresceu $39 \%$ em relação ao censo de 2000 , embora ainda continue sendo uma população invisibilizada e só recentemente tenha começado a ser estudada pela Psicologia. Como marcos da recente aproximação da Psicologia com a temática indígena, destacamos: o relatório do seminário "Subjetividade e Povos Indígenas" (2004) e o livro "Psicologia e Povo Indígenas" (2010). O objetivo deste estudo é atualizar o estado da arte sobre os povos indígenas na Psicologia no Brasil, considerando duas bases de dados o PePSIC e a SciELO. Utilizando como palavras-chave "indígena" ou "índio" em toda coleção na primeira base e somente nas revistas de Psicologia na segunda, encontramos um total de 25 artigos, os quais foram lidos na íntegra e agrupados de acordo com os temas estudados. Concluímos que os artigos encontrados se caracterizam, por um lado, pela interdisciplinaridade, e por outro, pela falta de um referencial teórico bemdefinido específico da área da Psicologia. Entendemos que a complexidade da temática demanda um olhar interdisciplinar, no entanto, a escassez de referências específicas da Psicologia nos indica que ainda temos muito a avançar, possivelmente pela aproximação recente da Psicologia com o estudo da temática e também pela própria constituição da Psicologia enquanto ciência pautada principalmente por tradições individualistas, que destoam das tradições indígenas que se baseiam principalmente no coletivismo.
\end{abstract}

Palavras-chave: Psicologia, Indígenas, Índios, Revisão de Literatura.

\section{A Brazilian Psychology and the Indigenous Peoples: Updating the State of Art}

\begin{abstract}
According to the last census of IBGE (2010a) 0,4\% of Brazilian population is composed of indigenous, this population has increased in recent years and grew $39 \%$ compared to the 2000 census, although they continue being a invisibly population and just recently has begun to be studied by Psychology. The landmarks of the recent approach of Psychology to indigenous issues, detached: the seminar report "Subjetividade e Povos Indígenas" (2004) and the book "Psicologia e Povos Indígenas" (2010). The goal of this study is to update the state of the art on indigenous peoples in Psychology in Brazil, considering PePSIC and SciELO databases. Using as keywords "indigenous" or "Indian" throughout all the collection in the first databases and only in psychological journals in the second, we found 25 papers that have been read in full and grouped according to the subjects studied. We concludes that the articles found are characterized, first, by interdisciplinary, and secondly, the lack of specific well-defined theoretical framework in the area of psychology. We understand the complexity of the subject demands an interdisciplinary approach, however the lack of specific references Psychology tells us that we still have much to learn, possibly by the recent approach of psychology to the subject and also by the very constitution of psychology as science guided mainly individualistic traditions that are different of indigenous traditions, which are based on collectivism.
\end{abstract}

Keywords: Psychology, Aboriginal, Indians, Literature Review. 


\title{
La Psicología Brasileña y los Pueblos Indígenas: Actualización del Estadio del Arte
}

\begin{abstract}
Resumen: Según el ultimo censo del IBGE (2010a) el 0,4\% de la población brasileña esta compuesta por indígenas, población esta que es cada vez mayor y creció $39 \%$ en relación al censo llevado a cabo en 2000, aunque continua a ser una población que no es visible y que solamente ahora empezó a ser estudiada por la Psicología. Como hitos de la reciente enfoque de la Psicología acerca de las cuestiones indígenas, destacamos: el informe del seminário "Subjetividade e Povos Indígenas" (2004) y el libro "Psicologia e Povo indígenas" (2010). El objetivo de este estudio es actualizar el estado del arte acerda de los pueblos indígenas en la Psicología brasileña, teniendo en cuenta dos bases de datos: PePSIC y SciELO. Las palabras clave utilizadas eran "indígenas" o "indios" a lo largo de la colección en la primera base y sólo en revistas de psicología en la segunda y se encontraron un total de 25 artículos que fueron leídos íntegramente y agrupados conforme el tema. Se concluí que los artículos encontrados son caracterizados por su interdisciplinariedad y por la escasez de referencias a las teorías bien definidas y específicas de la Psicología. Entendemos que la complexidad del tema necesita una mirada interdisciplinaria, sin embargo la escasez de referencias especificas de la Psicología, nos muestra que todavía hay mucho a avanzar, posiblemente por el aproximación recente de la Psicología a los estudios del tema y también por la propia constitución de la Psicología como ciencia basada principalmente en tradiciones individualistas que es diferente de las tradiciones indígenas, que son basadas en el colectivismo.
\end{abstract}

Palabras clave: Psicología, Indígenas, Indios, Revisión de la Literatura.

\section{Introdução}

Estima-se que quando os portugueses aqui aportaram, já viviam no território hoje abrangido pelo Brasil cerca de cinco milhões de indígenas, população que foi dizimada, primeiro pelas epidemias de pestes mortais e depois pelas guerras de extermínio e escravização (Ribeiro, 2013). Apesar disso, dados dos últimos censos mostram que a população indígena está em processo de crescimento no Brasil, como indicou o Censo 2010, que revelou um crescimento da população indígena muito superior à expectativa, passando de 294.000 para 734.000 pessoas em apenas nove anos (IBGE, 2010a).

Atualmente, de acordo com dados oficiais do Instituto Brasileiro de Geografia e Estatística (IBGE, 2010b), a população no Brasil é de 190.732 .694 habitantes, dos quais apenas $0,4 \%$ são indígenas, o que corresponde a 896.917 pessoas. Os indígenas no Brasil são de 305 etnias e falam mais de 274 diferentes línguas (IBGE, 2012), e o Estado do Amazonas é o que possui a maior população autodeclarada indígena do país: 168.680. Dos cinco municípios com maior número de habitantes indígenas, quatro estão no Estado do Amazonas (São Gabriel da Cachoeira, São Paulo de Olivença, Tabatinga e Santa Isabel do Rio Negro) e um é a cidade de São Paulo com
18.692 indígenas, sendo que sua população total é de 11.244.369 habitantes (IBGE, 2012).

Nos censos de 1991 e 2000, uma questão específica sobre raça e cor trouxe a possibilidade de a pessoa se autodeclarar: branca, amarela, preta, parda ou indígena. No censo de 2010 - diferentemente dos censos anteriores de 1991 e 2000 - , a pessoa que se autodeclarasse indígena deveria responder a questões específicas sobre sua etnia ou povo, assim como a língua falada, e referir se moravam em terras indígenas ou não, questões que não existiam nos censos anteriores (IBGE, 2010c). Até então, os dados oficiais sobre as etnias e línguas indígenas faladas no Brasil apresentavam divergências, o que mostra que o país desconhecia uma parcela de sua própria população, desconhecimento que não se revela somente em termos numéricos, mas também em termos históricos.

Somente com a Lei $\mathrm{n}^{\circ} 11.645$, de 10 de março de 2008 (Brasil, 2008), o ensino da história e das culturas negra e indígena tornou-se obrigatório nos currículos escolares. Esta inclusão recente reflete a própria inclusão tardia dos indígenas na historiografia brasileira. Segundo Monteiro (2001), foi somente a partir de meados do século XIX que a historiografia indígena começou a ser construída de forma mais definitiva, 
pois, até então, os historiadores consideravam que o tema era da alçada exclusiva da Antropologia.

A primeira História Geral do Brasil, escrita por Francisco Adolfo de Varnhagem em 1854-1857, apresentava os povos indígenas como se estes fossem "fósseis vivos de uma época remota" e "povos sem história e sem futuro" (Monteiro, 2001, p. 3). Os índios eram vistos como povos fadados à extinção e foram alvo de um intenso debate que atravessou o século XIX, entre aqueles que defendiam sua extinção e aqueles que defendiam sua assimilação ou "entre partidários da 'catequese e civilização' e os defensores do afastamento e mesmo do extermínio dos índios" (p. 4). Estas ideias repercutem até hoje na historiografia brasileira: índios não são atores históricos ou estão em vias de desaparecimento, no entanto, esta situação começou a mudar a partir da década de 1970, quando as preocupações teóricas se juntaram com preocupações militantes na defesa dos direitos indígenas e a teoria pôde ser repensada estimulada por esta nova situação. (Monteiro, 2001)

A defesa do extermínio dos índios enquanto proposta governamental também adentrou o século XX: segundo Maldos (2010), “[...] houve um plano oficial da Ditadura [1964-1985] de zerar a população indígena, de aniquilamento total" (p. 272). Recentemente, foi encontrado um documento com mais de 7.000 páginas, o Relatório Figueiredo (elaborado em 1967-68), que traz denúncias de tortura e práticas de extermínio executadas por um órgão oficial do governo, o antigo Serviço de Proteção ao Índio (SPI), que antecedeu a FUNAI. O relatório final elaborado pela Comissão Nacional da Verdade, que apurou as violações dos direitos humanos que ocorreram durante o período de ditadura militar no Brasil, traz um capítulo específico sobre as violações de direitos dos povos indígenas e mostra que estas violações por parte do Estado foram tanto violência direta quanto omissão. No período (entre 1946 e 1988) investigado pela comissão, ao menos 8.350 indígenas foram mortos pela ação direta do Estado ou por sua omissão, povos indígenas tiveram suas terras usurpadas, sofreram com transferencias forçadas e tentativas de extermínio com oferta de alimentos envenenados, contágios propositais e massacre com armas de fogo (Brasil, 2014).

No entanto, a proposta de extermínio não se concretizou e isto se deve à luta dos indígenas em parceria com universidades, igrejas e entidades da sociedade civil, luta que trouxe como conquista dois artigos (231 e 232) na Constituição Federal Brasileira de 1988 em relação ao reconhecimento: dos territórios indígenas, da diversidade cultural, do direito à participação na formulação das políticas públicas que lhe dizem respeito e de representarem a si próprios para interagir com o Estado, o que favoreceu, nos anos 1980, a formação de diversas organizações indígenas no país (Maldos, 2010).

É neste contexto de luta por reconhecimento e da atenção especial que deve ser oferecida aos povos indígenas que nos questionamos e nos propusemos a investigar o que está sendo produzido recentemente sobre os povos indígenas na Psicologia no Brasil.

\section{Método}

Esta pesquisa é um estudo do estado da arte. De acordo com Ferreira (2002), este tipo de pesquisa traz "[...] o desafio de mapear e de discutir uma certa produção acadêmica em diferentes campos do conhecimento, tentando responder que aspectos e dimensões vêm sendo destacados e privilegiados em diferentes épocas e lugares" (p. 258).

Os artigos foram pesquisados no ano de 2013 nos Periódicos Eletrônicos de Psicologia (PePSIC) e na Scientific Electronic Library Online (SciELO), duas bases de dados nacionais, de acesso livre e gratuito, que incluem as revistas mais importantes da Psicologia no Brasil. Para a realização da pesquisa na SciELO, as palavras-chave utilizadas foram Indígena e Psicologia. Estas palavras foram escritas no campo pesquisare marcamos como opção de busca todos os índices. Na base PePSIC, a palavra-chave utilizada para busca foi indígena, e os outros procedimentos foram os mesmos utilizados na base SciELO. Esta diferenciação se deve ao fato de que na base PePSIC os artigos pesquisados têm, necessariamente, vínculo com a Psicologia, portanto não é necessário usá-la como palavra a ser pesquisada.

Para busca na ScieLO, em que inicialmente utilizamos como palavras-chave Indígena e Psicologia, encontramos cinco artigos. Num segundo momento, fizemos uma busca nos periódicos da área da Psicologia com as palavras-chave Indígena ou Índio e chegamos a um total de 13 artigos. Na base PePSIC, em um segundo momento, utilizamos, além da palavra indígena, a palavra índio, e encontramos 12 artigos. Como resultado final das buscas realizadas foram encontrados, ao todo, 25 artigos. Todos os artigos foram lidos na íntegra e neles buscamos identificar: objetivo, método, 
referencial teórico, principais resultados e conclusões, assim como recomendações para a prática dos psicólogos que trabalham com povos indígenas.

Nossa busca ficou restrita a duas bases de dados (ScieLO e PePSIC), no entanto, encontramos um artigo de Vitale e Grubits (2009) que teve como base diferentes fontes documentais e bancos de dados eletrônicos - como o Portal Capes, a Biblioteca Digital de Teses e Dissertações (BDTD), a Biblioteca Virtual em Saúde-Psicologia (BVS-Psi) - além dos acervos eletrônicos de bibliotecas de 30 instituições de Ensino Superior do Brasil, que incluímos em nossa discussão.

Além dos artigos, foram incluídos na pesquisa o relatório do seminário "Subjetividade e Povos Indígenas" (2004) ${ }^{1}$ e o livro "Psicologia e Povos Indígenas" (2010), que possivelmente representam as duas primeiras produções da Psicologia no Brasil de sistematização de demandas e propostas de atuação do psicólogo junto aos povos indígenas. Nossa intenção não foi analisar estes materiais, mas sim divulgar e destacar as orientações aos psicólogos que atuam com os povos indígenas que eles contêm.

\section{Resultados}

Primeiramente apresentaremos uma síntese do relatório do seminário “Subjetividade e Povos Indígenas" e do livro "Psicologia e Povos Indígenas", destacando as orientações aos psicólogos que atuam com estas populações. Na sequência, apresentaremos, reunidos em grupos temáticos, os 25 artigos encontrados nas bases SciELO e PePSIC sobre populações indígenas em periódicos científicos da área da Psicologia.

\section{Psicologia e povos indígenas: orientações para prática do psicólogo}

O seminário "Subjetividade e Povos Indígenas" pode ser considerado um marco da aproximação da Psicologia brasileira com os povos indígenas de nosso país. Ele foi realizado pelo Conselho Federal de Psicologia (CFP) no ano de 2004 e teve como objetivo levantar questionamentos e identificar propostas que pudessem contribuir tanto para o trabalho do psicólogo quanto para respostas às demandas das comuni- dades indígenas e que visassem "contribuir no resgate da dívida histórica que a Psicologia possui com os povos indígenas em nosso país". Cumpre destacar que deste seminário participaram psicólogos e lideranças indígenas de várias etnias e estados brasileiros.

Como resultado deste seminário, o Conselho Regional de Psicologia de São Paulo (CRP-SP) criou o grupo de trabalho (GT) "Psicologia e Povos Indígenas" (CRPSP, 2010). Este grupo organizou vários encontros entre psicólogos, lideranças indígenas e outros profissionais. Os relatos destes encontros foram transformados no livro "Psicologia e Povos Indígenas", publicado no ano de 2010, disponível em formato eletrônico e impresso e distribuído gratuitamente. No livro são apresentados diversos objetivos, tais como: produzir referências para o exercício profissional do psicólogo; identificar áreas de atenção prioritária; consolidar práticas inovadoras e/ou reconhecer práticas tradicionais da psicologia; dar voz à categoria para que apresente suas posições e questões e reflita sobre elas, no sentido de construir coletivamente um projeto para a Psicologia que garanta o reconhecimento social de sua importância como ciência e profissão.

No livro (CRPSP, 2010) são apresentados diferentes discursos: dos representantes indígenas, de psicólogos, antropólogos e profissionais da saúde - cada um em sua especificidade, contribuindo para pensar a atuação do psicólogo junto aos povos indígenas. A partir das contribuições de cada participante, o GT, ao final do livro, recomenda aos psicólogos, no trabalho com as populações indígenas, o apoio às lutas e à educação diferenciada, a promoção de saúde mental a partir do enfoque psicossocial, a mediação de conflitos, a inclusão da temática indígena em espaços de debate e formulação de políticas públicas, a contribuição nas discussões interdisciplinares, além dos cuidados éticos necessários na realização de trabalhos com diferentes etnias.

Além dessas recomendações, as produções foram sistematizadas em três diferentes segmentos: problemas a serem enfrentados pela Psicologia e pelos psicólogos no atendimento aos povos indígenas; a necessidade de a Psicologia e os psicólogos criarem redes de atendimento a estes povos; e as contribuições que possam ser oferecidas pela Psicologia.

Como principais problemas a serem enfrentados, destacam-se: o desconhecimento das populações indígenas no que se refere às possibilidades de atuação

' Seminário Subjetividade e Povos Indígenas. Brasília, 2004. [Transcrição do evento]. 
do psicólogo, a dificuldade do psicólogo em trabalhar com um grupo que possui traços culturais diferentes dos seus, infraestrutura deficitária, linguagem diferenciada, enfoques epistemológicos distintos, além da falta de articulação entre as instâncias governamentais que promovem as políticas públicas.

No que diz respeito às contribuições, os psicólogos podem atuar no atendimento aos povos indígenas, na fomentação de diálogos, na superação de preconceitos e na criação de políticas públicas que considerem a diversidade cultural e a subjetividade destes povos. O psicólogo também podem ser incluído nas equipes de saúde, tendo como enfoque a saúde mental e o suporte emocional aos membros das equipes multiprofissionais que trabalham com estas populações, assim como na realização de ações conjuntas com educadores indígenas visando à melhoria na qualidade da educação ofertada a essa população.

Partindo destes apontamentos que são apresentados no livro, vale ainda destacar as colocações de Maldos (2010) de que a escuta é uma ferramenta fundamental no trabalho do psicólogo e que o seu papel no trabalho com povos indígenas está relacionado à construção de novas subjetividades e relações sociais que permitam a superação de ideologias baseadas na relação predatória do homem com a natureza, as quais foram consolidadas há tanto tempo. Uma alternativa para tal superação apresentada pelo autor é perceber as contribuições que minorias, como os povos indígenas, têm a nos oferecer na construção de uma relação mais harmônica com o mundo de modo geral, ou seja, o que podemos aprender com estas populações deve servir como promotor de mudanças nas relações sociais, de modo que estes povos que são considerados do passado passem a ser vistos como povos que têm uma grande contribuição a dar na construção do futuro.

\section{Os povos indígenas em pesquisas da área da Psicologia}

No levantamento realizado foram encontrados 25 artigos nas bases SciELO e PePSIC, os quais foram agrupados de acordo com os temas de que tratavam. Os temas encontrados foram: Infância e juventude (cinco artigos); Educação (quatro artigos); Comparações entre grupos indígenas e não indígenas (três artigos); Representações sociais dos indígenas (três artigos); Alcoolismo (dois artigos); Saúde (dois artigos); Relação estudantes/equipe de saúde e indígenas (dois artigos); e outros temas (quatro artigos). Buscamos identificar nestes artigos: objetivo, metodologia e principais resultados e conclusões.

\section{Infância, adolescência e juventude}

Cinco artigos abordam o tema "Infância, adolescência ou juventude", de maneira que Grubits e Darrault-Harris (2003) estudaram a construção da identidade de crianças indígenas Guarani/Kaiowá e Kadiwéu, do Mato Grosso do Sul. Entre os Kadiwéu, o difícil acesso à reserva e sua preservação ambiental, a exuberância $\mathrm{e}$ originalidade de suas cerâmicas, entre outros fatores, favorecem uma maior homogeneidade na expressão e conteúdo dos trabalhos. Além da afirmação da identidade étnica, foi possível perceber papéis bem-definidos do homem e da mulher quanto a trabalho e linguagem. Já entre os Guarani-Kaiowá foi observado que é comum a saída da reserva por parte dos homens para trabalhar nas cidades próximas, enquanto as mulheres permanecem na aldeia, protegendo assim grande parte de suas características culturais.

Grubits, Freire e Noriega (2011) buscaram compreender os motivos que levaram indígenas - especificamente os da etnia Guarani/Kaiowá do Mato Grosso Sul - a se suicidar. A população Guarani no estado, de acordo com dados de 2008, era de 40.025 indígenas, e destes, entre 2000 e 2008, 410 se suicidaram. A maioria dos suicídios ocorreu entre jovens do sexo masculino com menos de 29 anos. A explicação deste fenômeno geralmente está relacionada a fatores sociais, culturais, econômicos e políticos, embora as autoras também destaquem o feitiço, a sugestão, o processo de confinamento compulsório, a superpopulação no espaço delimitado para as aldeias, além das imposições culturais externas.

Azevedo e Adorno (2007) buscaram compreender os distintos significados atribuídos à maternidade pelas diferentes gerações Guarani-Mbyá em uma aldeia localizada na periferia da cidade de São Paulo. Os grupos entrevistados foram de jovens de 12 a 17 anos, mães de diferentes faixas etárias, professores, caciques (anterior e atual), agentes de saúde e parteira. Considerando que estes indígenas viviam em contato direto com padrões culturais urbanos, Azevedo e Adorno investigaram se os rituais indígenas ligados à reprodução se faziam presentes naquela aldeia. 
Os autores concluíram que a dimensão mítica e ritualística que envolve a maternidade ainda é presente na cultura Guarani, embora muitos de seus rituais tenham passado por mudanças. A primeira mudança diz respeito ao número de filhos, que tradicionalmente costumava ser grande, mas que agora aparece sob uma ótica de planejamento. A segunda mudança refere-se aos métodos contraceptivos: como os mais adotados atualmente são os métodos "dos brancos", as mulheres indígenas abandonaram o uso de ervas, como era o costume tradicional.

Buratto, Almeida e Costa (2012) fizeram um estudo de caso de uma adolescente Kaingang que apresentava deficiência intelectual e transtornos de linguagem. $\mathrm{O}$ instrumento utilizado pelas autoras foi o Sistema de Comunicação por Troca de Figuras (PECS) adaptado para o uso da adolescente, de modo que, para a readaptação, foram consideradas a cultura e a língua da etnia. De acordo com as autoras, poucos são os estudos sobre indígenas com deficiências, de modo que nesses casos há uma dupla discriminação do sujeito: por ser indígena e por ser deficiente. Os resultados obtidos mostraram que o uso do PECS provocou mudanças significativas em relação à comunicação da adolescente indígena com seus interlocutores.

Pinheiro e Frota (2009) analisaram o modo como a infância é vivenciada na cultura Jenipapo-Kanindé, tomando como base uma tribo indígena do Nordeste do Brasil. Foram utilizadas obervações de campo, entrevistas com adultos e crianças, além de desenhos feitos pelas crianças. As autoras destacam que, até a chegada da FUNAI, na década de 1990, o grupo indígena falava apenas português e não se reconhecia como indígena, embora também não se reconhecesse como branco. Sobre a vivência da infância na comunidade, Pinheiro e Frota perceberam que não existem assuntos de adultos e crianças e que estas tinham ampla participação nos assuntos discutidos na comunidade. No entanto, o lugar ocupado pela criança e no modo como a infância é vivenciada sofreu transformações ao longo dos anos. Estabelecendo uma comparação entre a comunidade estudada nos anos 1960 e a atual, a principal mudança identificada foi que as atividades laborais deixaram de fazer parte do dia a dia das crianças para dar lugar ao estudo e às brincadeiras, mudanças que coincidem com o início da atuação da FUNAI na comunidade. O brincar é entendido como o que diferencia a criança do adulto e, nesta comunidade, esta atividade se dá de forma mais livre do que nas comunidades próximas, uma vez que fortes vínculos ligam família e comunidade, a comunidade como um todo é responsável pelo cuidado das crianças. Para concluir, as autoras destacam que é necessário considerar o que as crianças têm a dizer de si mesmas e desconstruir a ideia de infância como categoria universal.

\section{Educação}

Os artigos sobre o tema Educação abordam, mesmo que de diferentes formas, a necessidade de uma educação diferenciada para indígenas, que considere as diferenças culturais destes povos. Os artigos sobre o tema são de Silva Junior (2000); Brostolin (2007); Brostolin e Cruz (2009; 2010). Estes três últimos artigos são sobre a etnia Terena e abordam o ensino e aprendizagem dos indígenas pertencentes a esta etnia, que é a segunda maior do Mato Grosso do Sul.

Brostolin (2007) apresenta um estudo de caso que teve como objetivo identificar o método de ensino empregado pelo professor, analisar a relação professor/aluno, assim como o significado de aprender para o professor e para os alunos indígenas. Segundo a autora, o ensino formal não reflete os interesses e a realidade das comunidades indígenas, em que a educação se dá no contato das crianças com as atividades diárias dos adultos, em rituais e em comemorações. Resgatando, brevemente, a história da educação indígena, a divide em quatro momentos: primeiro, na época colonial com os jesuítas; segundo, a partir de 1910 com a criação do SPI; terceiro, a partir da década de 1970 com as Organizações não Governamentais (ONG) voltadas para causas indígenas e quarto, a partir da década de 1980, com a articulação dos povos indígenas que conquistam, na década de 1990, uma nova legislação escolar que propõe a educação diferenciada, intercultural e bilíngue. No estudo de caso, Brostolin conta que, na aldeia estudada, a primeira escola chegou na década de 1930 e não ensinava a língua materna, o que trouxe como consequência o seu quase desaparecimento, assim como dos conhecimentos tradicionais que também não eram ensinados na escola. Atualmente, a escola busca integrar os conhecimentos tradicionais aos conhecimentos escolares.

Brostolin e Cruz (2009; 2010) destacam que a educação cada vez mais vem sendo percebida como um instrumento de empoderamento na luta pela garantia de direitos e que devem ser consideradas as 
diferenças culturais na forma de aprender e ensinar, diferenças que vão desde os aspectos antropológicos até os históricos e psicopedagógicos de cada povo.

O artigo de Silva Junior (2000) teve como objetivo investigar a contribuição da Psicologia na educação indígena. A metodologia adotada foi a pesquisa bibliográfica e entrevistas com profissionais da área. $\mathrm{O}$ autor conclui que a contribuição da Psicologia deve ter duas direções: uma voltada para a própria comunidade na manutenção e recuperação da identidade indígena e na preparação dos professores e outra para fora da comunidade indígena, com a sensibilização dos não índios sobre a importância da educação indígena.

\section{Comparação entre grupos indígenas e não indígenas}

Andrade e Bueno (2007) avaliaram a cognição de 12 indígenas e 12 não indígenas moradores da periferia da cidade de São Paulo, utilizando como instrumento os testes Dígitos, Blocos de Corsi, Desenho com Cubos e Nomeação de Figuras, e concluíram que não existiam diferenças significativas entre os grupos, porém, constataram uma tendência dos indígenas a mostrar um maior domínio das tarefas visuais e motoras, e, nos não indígenas, um maior domínio das tarefas verbais. Embora os dois grupos se mostrassem motivados e engajados nas tarefas, as palavras e atitudes dos índios demonstravam que estes se divertiam com a situação, sem se importar tanto com erros e dificuldades; já para os não índios, os erros eram percebidos como fracasso e eram verbalizados pelos sujeitos.

Gosso, Morais e Otta (2006) investigaram as apropriações de objetos nas transformações simbólicas executadas em contexto de brincadeiras entre crianças de cinco grupos culturais diferentes no Brasil, entre elas um grupo de crianças indígenas da aldeia Paranowaona, de Ubatuba, São Paulo. Participaram do estudo 76 crianças com idade de quatro a seis anos e o método adotado para coleta de dados foi a observação e registro das brincadeiras. Segundo as autoras, os brinquedos, por um lado, são símbolos sociais que fazem referências específicas a determinadas atitudes e práticas sociais e, por outro, são ferramentas utilizadas pelas crianças para expressar a sua imaginação de forma autônoma. Os resultados indicam que as crianças refletem nas suas brincadeiras sua individualidade e os valores de sua cultura, de modo que entre os indígenas prevaleceu o uso de utensílios como pivôs nas brincadeiras. Isto levanta a hipótese da proximidade destas crianças com o trabalho adulto, a qual levaria a uma maior familiaridade com estes materiais.

Figueiredo (2009) discorre sobre a forma como se compreende e utiliza a escrita na cultura indígena Aweti, do Alto Xingu no Mato Grosso, comparando com a cultura não indígena. A autora conclui que, para a cultura indígena, a escrita não tem a mesma importância e significado que tem para a cultura ocidental, uma vez que a fala e a escuta são as formas mais utilizadas pelos primeiros de se comunicar. Para o grupo indígena estudado, a escrita é entendida como instrumento necessário para comunicação com não indígenas e não como algo que torna o homem branco superior ao indígena.

\section{Representações sociais}

Lima e Almeida (2010) entrevistaram 378 moradores de seis cidades do estado de Sergipe com objetivo de investigar as representações sociais construídas pelos sergipanos sobre os indígenas. Entrevistas com perguntas abertas e fechadas foram utilizadas na coleta dos dados. Os resultados obtidos mostram a representação histórica do índio construída pelos sergipanos é predominantemente de um índio distante física, histórica e culturalmente, ou seja, que não sofreu atualizações históricas. Este tipo de representação é comum mesmo entre aqueles que vivem próximos a grupos indígenas. A representação do indígena que aparece como atual é ambivalente: o indígena como excluído e carente de direitos ou aproveitador das políticas públicas. Os autores concluem que, em nosso país, os indígenas permanecem ignorados, desconhecidos e estrangeiros. A representação social do índio ausente, homogêneo e quase inexistente é veiculada pelos meios de comunicação de massa.

Braga e Campos (2012) discutem como os veículos de mídia de massa elaboram os discursos que construíram uma realidade particular, independentemente dos atores sociais envolvidos. Os autores analisaram 226 notícias publicadas em um jornal de circulação nacional sobre a demarcação e desocupação da Reserva Raposa Serra do $\mathrm{Sol}^{2}$ e identificaram

\footnotetext{
${ }^{2}$ Trata-se de um processo judicial que teve início nos anos 1970 e só foi solucionado no ano de 2009, quando o Tribunal Superior Federal aprovou a reserva como propriedade indígena, levando assim à sua desocupação por parte dos agricultores nela presentes.
} 
um discurso de ocupação produtiva e a ausência da voz dos indígenas. Braga e Campos, constataram os discursos não revelados, ou seja, discursos que são incluídos ou excluídos a fim de consolidar determinados conteúdos, e notícias silenciadas, que são aquelas que pareciam omitir intencionalmente atores sociais do relato do caso em questão. A invisibilidade e subalternidade do indígena no âmbito da mídia indicam um conjunto de representações que permeia a memória coletiva dos sujeitos não indígenas.

Maciel, Oliveira e Melo (2012) investigaram as representações sociais de profissionais de saúde sobre o uso abusivo de álcool pelos índios Potiguara, no estado da Paraíba. Foram entrevistados 21 profissionais de saúde. Os resultados indicam que o uso abusivo de álcool é entendido pelos profissionais de saúde como um problema grave de saúde que atinge a população indígena, juntamente com as DST/AIDS e a gravidez precoce. $\mathrm{O}$ alcoolismo é atribuído à aculturação dos indígenas, associada à diversão de fácil acesso. Segundo as autoras, fica evidenciada pela pesquisa a necessidade de uma compreensão mais ampla deste fenômeno do alcoolismo em comunidades indígenas, visto que na sociedade esse é um problema de saúde pública que atinge a todos, gerando maiores problemas de ordem social e pessoal. Em conclusão, Maciel et al. destacam a necessidade de pesquisas mais amplas na área para dimensionar a questão do uso abusivo do álcool e os problemas de saúde a ele vinculados, além de gerar informações que possam servir de base para a implantação de serviços de atenção básica à saúde acerca dessa problemática.

\section{Alcoolismo}

Melo, Maciel, Oliveira e Silva (2011) fizeram sua pesquisa com os Potiguara do estado da Paraíba e investigaram o consumo de álcool entre os indígenas, com objetivo de conhecer melhor esta população e contribuir com a implantação de serviços de atenção básica junto a esta população. Neste estudo foram entrevistados 55 indígenas maiores de 18 anos e de ambos os sexos, dos quais $41,8 \%$ responderam que pelo menos um membro da família fazia uso de bebidas alcoólicas e $27,3 \%$ afirmaram que a bebida traz diversos problemas para a família. Na comunidade estudada, o uso do álcool ocorria em idade precoce, desvinculado da cultura e de forma abusiva. As autoras identificaram que o consumo de álcool estava relacionado ao processo de aculturação, à proximidade a usinas e engenhos de álcool, à instalação de bares e restaurantes dentro da aldeia e ao turismo desordenado. O enfrentamento desta situação demanda situação um trabalho de resgate da cultura, de prevenção e promoção de saúde, compreendendo-se a saúde em seu sentido mais amplo, além da necessidade de serem desenvolvidos estudos mais amplos, que abarquem a temática da saúde e os aspectos socioculturais deste povo, envolvendo não apenas o consumo de álcool, mas também a presença de outras drogas.

$\mathrm{O}$ artigo "Aspectos psicológicos na utilização de bebidas alcoólicas" entre os Karitiana, de Vianna, Cedaro e Ott (2012), buscou compreender os modos de utilização de bebidas alcoólicas entre os Karitiana, privilegiando os aspectos psicológicos envolvidos nesse processo e refletindo sobre possibilidades de atuação psicológica entre povos indígenas. A metodologia adotada foi composta por entrevistas e observação participante. Segundo os autores, o alcoolismo tem causado diversos problemas a estas populações: desagregação das aldeias, aumento da violência, agressões, acidentes e até mesmo homicídios e suicídios. O uso indiscriminado da bebida no grupo estudado foi na década de 1960-1970, período que coincide com intensa atividade de garimpo e extração da madeira no local, o que demandou a conscientização e elaboração de estratégias das lideranças locais para conter o uso indiscriminado do álcool, estratégias que deram resultados, uma vez que o uso do álcool na atualidade está controlado.

Frente a este contexto, os autores elaboraram algumas recomendações para os psicólogos que atuam junto a povos indígenas entre os quais bebidas alcoólicas são usadas de modo abusivo, tais como: considerar as especificidades culturais da etnia estudada, pois não existe um "índio genérico"; considerar o beber coletivo e não o indivíduo isolado; não aplicar técnicas indiscriminadamente, desconsiderando as organizações e hierarquias locais; compreender o “beber-problema” não como "disposição de indivíduos que sucumbem ao vício, mas sim de um grupo exposto a um contexto hostil que os torna vulneráveis" (p. 102).

Segundo Vianna et al. (2012), a Psicologia "euro-americana" tem como premissas socioculturais as tradições do individualismo, liberalismo e racionalidade, de modo que, ao trabalhar em uma sociedade que se baseia na coletividade, a perspectiva e 
a possível intervenção deverão sempre ser comunitárias, do contrário será inviável e incongruente. Os autores concluem que, no estádio atual de conhecimento, a Psicologia tem muito mais a aprender com os indígenas do que a ensinar; por isso é fundamental a realização de um esforço para compreender o contexto antes de intervir, e para esta compreensão é fundamental recorrer também a outras disciplinas, como a Antropologia e a Saúde Pública.

\section{Saúde}

Adorno e Pícoli (2008) estudaram as práticas de saúde e cuidado utilizadas pelos Kaiowá e Guarani no enfrentamento das doenças diarreicas na infância, com objetivo de compreender como as práticas indígenas se relacionam com as práticas biomédicas. A metodologia adotada foi a utilização de entrevistas abertas como moradores da comunidade e observação participante. No grupo estudado, a causa da diarreia é associada à criança fazer movimentos bruscos após comer alguma coisa e ao desmame, embora também a precariedade no saneamento básico também seja percebida como causa. Os tratamentos utilizados pelos indígenas para diarreia são plantas medicinais e chás muitas vezes acompanhadas por rezas. $\mathrm{O}$ conhecimento destas práticas pela equipe de saúde que irá intervir junto à comunidade é fundamental, uma vez que a intervenção da equipe implica um processo de negociação entre as culturas. Os autores recomendam que os tratamentos de saúde oferecidos às populações indígenas não podem ser calcados apenas em um modelo biomédico, mas devem também dialogar com a percepção e as práticas indígenas na identificação da causalidade, na definição do diagnóstico e do tratamento, sobretudo pela coexistência destas práticas no contexto local.

Já Gutierrez, Minayo e Oliveira (2012) investigaram o lugar do homem em relação aos cuidados com a saúde em famílias de baixa renda na Amazônia. As autoras entrevistaram 11 homens e suas famílias e 21 profissionais da saúde e concluíram que o cuidado de si dos homens é superficial, emergencial e mediado pela mulher e que o cuidado com os outros passa pelo papel de provedor. Os homens que fugiram a este padrão foram aqueles em que predomina a cultura indígena e jovens com visão social e familiar mais moderna.

\section{Relações dos estudantes e equipes de saúde com as populações indígenas}

O tema "relação dos estudantes e da equipe de saúde com os indígenas" foi identificado nos artigos de Macedo, Bairrão, Mestriner e Mestriner Junior (2011) e de Girão e Ernandes (2006). Macedo et al. (2011) relataram a experiência de acompanhamento de um estágio de estudantes de Odontologia e as questões que emergiram sobre os encontros interculturais, que trouxeram as questões do encontro com o outro (estranho) e suas implicações no confronto de cada um consigo mesmo. $\mathrm{O}$ artigo aborda especificamente uma reunião de uma equipe composta por estudantes, psicóloga e docente no retorno do Parque Indígena do Xingu e os sentimentos de medo, insegurança e fascínio que emergiram no contato com o outro. Os autores destacam a importância da inclusão de profissionais com formação em Etnopsicologia nas equipes e da escuta como ferramenta que pode auxiliar na formação das equipes de saúde, capacitando-as para encontros interculturais.

Girão e Ernandes (2006) também apresentaram um relato de experiência de uma equipe multiprofissional que atuava junto a jovens indígenas de uma reserva no Mato Grosso do Sul. O projeto apresentado no artigo teve como objetivo transformar a relação entre indígenas (das etnias Terena, Kaiowá e Ñandeva) e o ambiente urbano, uma vez que os grupos étnicos com os quais se trabalhou pertence a aldeias que são próximas a cidades. Dessa forma, como resultado do projeto, eles abordam a importância da relação estabelecida entre a equipe multidisciplinar e os jovens indígenas e da troca de experiências vivenciadas nesse relacionamento, destacando o aprendizado que se tornou possível através das diferenças entre os sujeitos envolvidos.

\section{Outros temas}

No artigo de Grubits, Darrault-Harris e Pedroso (2005) foi investigada a participação política da mulher nas comunidades indígenas Bororo, de Mato Grosso, e Guarani/Kaiowá e Kadiwéu, do Mato Grosso do Sul. Nos Bororo, a valorização de uma mulher da comunidade estava relacionada ao fato de ela ser guardiã da cultura e ao mesmo tempo interlocutora com a sociedade envolvente. Entre os Guarani/Kaiowá, enquanto os homens saíam das reservas, as mulheres ficavam e eram as mantenedoras da identidade Guarani; já entre os Kadiwéu, mesmo diante da divisão de funções, as 
mulheres tinham seus papéis igualmente valorizados. Os autores identificaram que, mesmo entre etnias com diferentes características, um ponto em comum é que as mulheres têm desempenhado papéis fundamentais na manutenção da cultura de seus povos diante das mudanças impostas pela sociedade envolvente e pelas políticas destinadas a estas comunidades.

Bernardes, Marques e Mázaro (2011) apresentam uma pesquisa de revisão bibliográfica de artigos científicos publicados após a Política Nacional de Atenção Integral à Saúde dos Povos Indígenas. Foram incluídos na pesquisa artigos sobre saúde indígena publicados entre 2000 a 2009, além de textos sobre políticas públicas relacionados a temática.

Rosa, Garcia e Leal (2007) apresentam uma reflexão sobre a política social tendo como foco de análise um contexto de luta pela posse de terras entre uma comunidade indígena (Guarani e Tupiniquins) e uma grande empresa brasileira de celulose, no Espírito Santo. Os indígenas reivindicavam a demarcação de suas terras e o conflito já ocorria há algumas décadas, quando, em 20 de janeiro de 2006, os indígenas tiveram suas casas destruídas. As autoras analisaram publicações da mídia local sobre o ocorrido em 2006 e destacam a desigualdades de forças no confronto e o uso da terra mascarando o conflito entre duas lógicas de uso da terra.

Por fim, Mindlin (2011) apresenta dois mitos indígenas, um dos Yamana da Terra do Fogo e outro dos Maxacali de Minas Gerais, que têm como tema comum o incesto entre mãe e filho, buscando pensar como é o amor no imaginário indígena.

\section{Discussão}

Vitale e Grubits (2009) realizaram um levantamento bibliográfico semelhante ao aqui apresentado, tratado no artigo "Psicologia e Povos Indígenas: um estudo preliminar do estado da arte”. Este artigo buscou apresentar um quadro geral das produções científicas na área da Psicologia relacionadas à temática indígena realizando uma análise dos resumos das produções localizadas em diferentes fontes documentais e bancos de dados eletrônicos - como o Portal Capes, a Biblioteca Digital de Teses e Dissertações (BDTD), a Biblioteca Virtual em Saúde-Psicologia (BVS-Psi) - além dos acervos eletrônicos de bibliotecas de 30 Instituições de Ensino Superior do Brasil.
Enquanto Vitale e Grubits (2009) buscaram as contribuições da Psicologia para os estudos sobre povos indígenas em teses, dissertações, monografias e relatórios científicos e identificaram 49 produções acadêmicas, nesta pesquisa buscamos artigos científicos publicados em periódicos da área da Psicologia disponibilizados nas bases SciELO e PePSIC e encontramos 25 artigos científicos. Vitale e Grubitz trabalharam com resumos e nesta pesquisa trabalhamos com artigos completos. As diferentes bases de dados e materiais pesquisados tornam estas pesquisas complementares e possibilitam a realização de comparações entre os resultados encontrados tanto em uma quanto na outra, o que será apresentado a seguir.

Na pesquisa de Vitale e Grubits (2009), assim como na nossa, constatou-se o aumento recente do interesse do psicólogo pela temática indígena. Segundo Vitale e Grubtis, foi a partir da década de 1990 que a Psicologia começou a se interessar pela temática, porém esta produção tornou-se mais significativa na última década, quando os trabalhos praticamente triplicaram em relação ao período anterior. Em nossa pesquisa, encontramos cinco artigos publicados de 2000 a 2006 e 20 de 2007 a 2012, o que mostra que o interesse pela temática é crescente; no entanto, o desconhecimento quase completo da totalidade destas produções é um dos problemas para a interlocução entre pesquisadores e para o próprio avanço das pesquisas na área, segundo Vitale e Grubits (2009).

No tocante aos fundamentos teóricos dos artigos que encontramos, uma marca é a interdisciplinaridade, de modo que são frequentes as referências a textos e autores das áreas da Antropologia, da Educação e da Saúde; porém, sentimos falta de referências a textos e autores específicos da área da Psicologia, que não encontramos em grande parte dos artigos. Resultado semelhante também obtiveram Vitale e Grubits (2009), as quais identificaram que em aproximadamente $83,67 \%$ dos resumos por elas analisados não citavam nomes de teóricos específicos da área da Psicologia.

Entendemos que esta ausência de referências a autores da Psicologia em produções da própria disciplina se deve ao fato de ser recente sua inserção no estudo da temática e de que as teorias psicológicas terem sido criadas a partir da cultura ocidental, de modo que sua aplicação em populações origi- 
nárias se torna um desafio. Neste mesmo sentido, Vianna et al. (2012) ressaltam a dificuldade em utilizar referenciais característicos de sociedades ocidentais em populações originárias, como no caso das culturas indígenas, uma vez que estes referenciais são baseados principalmente em tradições individualistas, que destoam das tradições indígenas, as quais se baseiam principalmente no coletivismo.

Além de buscar identificar os fundamentos teóricos dos artigos, também procuramos identificar quais etnias são objeto de estudo dos artigos. As etnias estudadas foram: Potiguara, Karitiana, Guarani, Kaingang, Bororó, Guarani/Kaiowá, Kadiwéu, Aweti, Jenipapo-Kanindé, Paranoawona, Maxacali, Aruak e Tupiniquim. A apresentação da etnia estudada já aparece no título dos artigos, e apenas três dos 25 artigos selecionados abordam a questão indígena sem se referir a uma etnia específica. Nas produções estudadas por Vitale e Grubits (2009), grande parte dos autores também apresenta já no título da produção a etnia com a qual trabalharam, o que é por elas considerado como fundamental, uma vez que não existe um "índio genérico" e cada etnia apresenta suas características e particularidades. Vitale e Grubits (2009) recomendam o maior detalhamento possível no que diz respeito à etnia que se encontra no foco da pesquisa, mas também o uso de termos generalizantes (como indígena), pois estes servem como facilitadores na localização das produções. A não utilização de termos generalizantes dificulta a identificação das pesquisas da área por outros pesquisadores.

No tocante às propostas apresentadas nas conclusões dos artigos, foi observado que estas, em sua maioria, são generalistas e geralmente não indicam aspectos específicos a serem trabalhados por profissionais e pesquisadores da Psicologia junto às populações indígenas, aspecto que acentua quanto ainda precisamos avançar neste campo de estudo.

\section{Considerações Finais}

O objetivo aqui proposto foi atualizar o estado da arte sobre os povos indígenas na Psicologia no Brasil. A conclusão foi que, mesmo não sendo este um campo muito explorado no meio acadêmico, os estudos direcionados a esta temática vêm gradualmente ocupando mais espaço. Esse crescente interesse por esta temática pode ser observado na maior quantidade de publicações a partir do ano de 2007, embora a maioria destes artigos não apresente um referencial teórico bem-definido nem obras de referência da área da Psicologia, o que indica que este é ainda um campo a ser explorado pela Psicologia brasileira. Embora esta pesquisa tenha sido restrita ao Brasil, convém destacar que seria importante para o desenvolvimento destes estudos no Brasil investigar a produção na área em outros países, tarefa que não realizamos aqui. A Austrália, por exemplo, já possui uma associação de psicólogos indígenas, a AIPA (Australian Indigenous Psichologists Association) que é voltada para o bem-estar emocional, social e para saúde mental das populações indígenas.

Como mostram Vianna et al. (2012), a Psicologia brasileira tem como base o modelo ocidental de pensamento, um modelo que compreende o sujeito como individualizado; mas esse modelo precisaria sofrer alterações ao lidar com povos indígenas, uma vez que estas sociedades se baseiam na coletividade e possuem uma compreensão de mundo diferente da ocidental. Nesse aspecto podemos salientar a importância da interdisciplinaridade para a superação desses limites, considerando que outras ciências - principalmente a Antropologia - podem auxiliar na formação de uma Psicologia que seja mais condizente com a realidade e as demandas das populações indígenas. A Psicologia tem muito a aprender com outras disciplinas - e não somente com elas, mas também com os povos indígenas.

Em relação aos psicólogos que trabalham com povos indígenas, destacamos a necessidade de conhecerem e respeitarem as especificidades culturais das etnias com os quais trabalham. Em outras palavras, é necessário que o psicólogo, ao entrar em contato com essas populações, esteja aberto ao modo como elas compreendem o mundo, servindo de mediador entre culturas e possibilitando um diálogo que permita realizar um trabalho em que ambas as partes - tanto o profissional quanto a população envolvida - contribuam com seus conhecimentos.

Para concluir, gostaríamos de destacar a realização do seminário "Subjetividade e Povos Indígenas" pelo CFP, os encontros realizados pelo GT "Psicologia e Povos Indígenas", o livro "Psicologia e Povos Indígenas" e, mais recentemente, o "I Encontro Nacional de Psicologia, Povos Indígenas e Direitos Humanos/II Seminário de Saúde 
Mental Indígena", ocorrido no ano de 2013 no Mato Grosso do Sul, como iniciativas que visam à interlocução com os povos indígenas, psicólogos e demais profissionais que trabalham com estas populações e que produziram referências para atuação do psicólogo junto aos povos indígenas. Destacamos também o trabalho de Vitale e Grubtis (2009), ao

\section{Referências}

Adorno, R. C. F., \& Pícoli, R. P. (2008). Cuidado à saúde de crianças kaiowá e guarani: notas de observação de campo. Revista Brasileira de Crescimento e Desenvolvimento Humano, 18(1), 35-45. Recuperado de http:// pepsic.bvsalud.org/scielo.php?script=sci_arttext\&pi$\mathrm{d}=$ S0104-12822008000100006\&lng=pt\&nrm=iso

Andrade, V. M., \& Bueno, O. F. A. (2007). Neuropsicologia transcultural: grupo indígena guarani. Estudos em Psicologia (Natal), 2(3), 253-258. doi:10.1590/S1413-294X2007000300007

Azevedo, M. A. P., \& Adorno, R. C. F. (2007). Juventude e reprodução entre os Guarani-Mbyá da Aldeia Morro da Saudade na periferia da cidade de São Paulo. Revista Brasileira de Crescimento e Desenvolvimento Humano, 17(2),64-73. Recuperado de http://pepsic.bvsalud.org/scielo.php?script=sci_arttext $\&$ pi$\mathrm{d}=\mathrm{S} 0104-12822007000200009 \& \operatorname{lng}=\mathrm{pt} \& \mathrm{nrm}=$ iso

Bernardes, A. G., Marques, C. F., \& Mázaro, L. P. (2011). A diferença tornada tradicional: formas de objetivação de populações indígenas. Estudo e Pesquisa em Psicologia, 11(3), 913-932. Recuperado de http:// pepsic.bvsalud.org/scielo.php?script=sci_arttext\&pi$\mathrm{d}=$ S1808-42812011000300011\&lng=pt\&nrm=iso

Braga, C. F., \& Campos, P. H. F. (2012). Invisíveis e subalternos: as representações sociais do indígena. Psicologia \& Sociedade, 24(3), 499-506. doi:10.1590/S0102-71822012000300003

Brasil. (2014). Comissão Nacional da Verdade. Relatório (vol. 2: textos temáticos). Brasília, DF: o autor. Recuperado de http://www.cnv.gov.br/images/pdf/ relatorio/volume_2_digital.pdf

Brasil. (2008). Lei $\mathrm{n}^{\circ} 11.645$, de 10 de março de 2008. Altera a Lei no 9.394, de 20 de dezembro de 1996, modificada pela Lei no 10.639 , de 9 de janeiro de 2003, que estabelece as diretrizes e bases da educação nacional, para incluir no currículo oficial da levantarem as pesquisas realizadas pela Psicologia junto aos povos indígenas com objetivo semelhante ao nosso. Recomendamos a leitura destas produções aos psicólogos e pesquisadores da área que se interessem pela temática. Esperamos também poder ter oferecido alguma contribuição neste campo da Psicologia.

rede de ensino a obrigatoriedade da temática "História e Cultura Afro-Brasileira e Indígena”. Diário Oficial da União, 11 mar. 2008.

Brostolin, M. R. (2007). Etnoeducação: uma análise a partir do gênero de ensino e sua articulação com o estilo de aprendizagem terena. Construção Psicopedagogica, 15(12), 106-121. Recuperado de http:// pepsic.bvsalud.org/scielo.php?script=sci_arttext\&pi$\mathrm{d}=$ S1415-69542007001100008\&lng=pt\&nrm=iso

Brostolin, M. R., \& Cruz, S. F. (2009). Estilos de aprendizagem e de ensinagem na escola indígena Terena. Construção Psicopedagogica, 17(14), 24-43. Recuperado de http://pepsic. bvsalud.org/scielo.php?script=sci_arttext\&pi$\mathrm{d}=$ S1415-69542009000100004\&lng=pt\&nrm=iso

Brostolin, M. R., \& Cruz, S. F. (2010). Ética e educação indígena: reflexões sobre os sentidos do aprender num contexto cultural diferenciado. Construção Psicopedagogica, 18(16), 45-54. Recuperado de http:// pepsic.bvsalud.org/scielo.php?script=sci_arttext\&pi$\mathrm{d}=$ S1415-69542010000100005\&lng=pt\&nrm=iso

Buratto, L. G. , Almeida, M. A., \& Costa, M. P. R. (2012). Programa de comunicação alternativa readaptado para uma adolescente kaingang. Paidéia (Ribeirão Preto), 22(52), 229-240. doi:10.1590/S0103-863X2012000200009

Conselho Regional de Psicologia de São Paulo - CRPSP. (2010). Psicologia e povos indígenas. São Paulo: o autor. Recuperado de http:/ / www.crpsp.org.br/povos/ povos/livro.pdf

Ferreira, N. S. A. (2002). As pesquisas denominadas "estado da arte". Educação \& Sociedade, 23(79), 257-272. doi:10.1590/S0101-73302002000300013

Figueiredo, M. V. (2009). Escrever, ouvir: perspectivas sobre o saber entre os Aweti do Alto Xingu. Ide (São Paulo), 32(48), 147-162. Recuperado de http://pepsic.bvsalud.org/scielo.php?script=sci_arttext\&pi$\mathrm{d}=$ S0101-31062009000100017\&lng=pt\&nrm=iso 
Girão, S. A., \& Ernandes, M. A. (2006). Construindo o "nós": o trabalho de uma equipe - na reserva indígena de dourados MS - por uma antropologia das negociações culturais. Imaginário, 12(12), 287-293. Recuperado de http://pepsic. bvsalud.org/scielo.php?script=sci_arttext\&pi$\mathrm{d}=$ S1413-666X2006000100015\&lng=pt\&nrm=iso

Gosso, Y., Morais, M. L. S., \& Otta, E. (2006). Pivôs utilizados nas brincadeiras de faz-de-conta de crianças brasileiras de cinco grupos culturais. Estudo em Psicologia (Natal), 11(1),17-24. doi:10.1590/S1413-294X2006000100003

Grubits, S., \& Darrault-Harris, I. (2003). Ambiente, identidade e cultura: reflexões sobre comunidades Guarani/Kaiowá e Kadiwéu de Mato Grosso do Sul. Psicologia e Sociedade, 15(1) 182-200. doi:10.1590/S0102-71822003000100010

Grubits, S., Freire, H. B. G., \& Noriega, J. A. V. (2011). Suicídio de jovens Guarani/Kaiowá de Mato Grosso do Sul, Brasil. Psicologia: Ciência \& Profissão, 31(3), 504-517. doi:10.1590/S1414-98932011000300006

Grubits, S., Darrault-Harris, I., \& Pedroso, M. (2005). Mulheres indígenas: poder e tradição. Psicologia em Estudo, 10(3), 363-372. doi:10.1590/S1413-73722005000300004

Gutierrez, D. M. D., Minayo, M. C. S., \& Oliveira, K. N. L. C. (2012). Homens e cuidados de saúde em famílias empobrecidas na Amazônia. Saúde e Sociedade, 21(4),871-883.doi:10.1590/S0104-12902012000400007

Instituto Brasileiro de Geografia e Estatística - IBGE. (2010a), Indigenas. Estudos especiais: o Brasil indígena. Rio de Janeiro, RJ: o autor. Recuperado de http://indigenas.ibge.gov.br/estudos-especiais-3/o-brasil-indigena Instituto Brasileiro de Geografia e Estatística - IBGE. (2010b). Censo demográfico 2010. Rio de Janeiro, RJ: o autor. Recuperado de http://www.ibge.gov.br/home/ estatistica/populacao/censo2010/default.shtm Instituto Brasileiro de Geografia e Estatística - IBGE. (2010c), Indigenas. Entrevista Nilza Pereira [vídeo]. Rio de Janeiro, RJ: o autor. Recuperado de http:// indigenas.ibge.gov.br/video-2

Instituto Brasileiro de Geografia e Estatística - IBGE. (2012). Os indígenas no senso demográfico 2010: primeiras considerações com base no quesito cor ou raça. Rio de Janeiro: o autor. Recuperado de http:// www.ibge.gov.br/indigenas/indigena_censo2010.pdf

Lima, M. E. O., \& Almeida, A. M. M. (2010). Representações sociais construídas sobre os índios em Sergipe: ausência e invisibilização. Paidéia (Ribeirão Preto), 20(45), 17-27. doi:10.1590/S0103-863X2010000100004

Macedo, A. C., Bairrão, J. F. M. H., Mestriner, S. F., \& Mestrine Junior, W. (2011). Ao encontro do Outro, a vertigem do eu: o etnopsicólogo em equipes de saúde indígena. Revista SPAGESP, 12(2), 85-96. Recuperado de http://pepsic.bvsalud.org/scielo.php?script=sci_arttext\&pi$\mathrm{d}=$ S1677-29702011000200009\&lng=pt\&nrm=iso

Maciel, S. C., Oliveira, R. C. C., \& Melo, J. R. F. (2012). Alcoolismo em indígenas potiguara: representações sociais dos profissionais de saúde. Psicologia: Ciência e Profissão, 2012, 32(1), 98-111. doi:10.1590/S1414-98932012000100008

Maldos, P. R. M. A contribuição indígena na construção do nosso futuro comum. In Conselho Regional de Psicologia de São Paulo - CRPSP. (2010), Psicologia e povos indígenas (pp. 272-278). São Paulo: o autor.

Melo, J. R. F., Maciel, S. C., Oliveira, R. C. C., \& Silva, A. O. (2011). Implicações do uso do álcool na comunidade indígena Potiguara. Physis, 21(1), 319-333. doi: 10.1590/S0103-73312011000100019

Mindlin, B. (2011). O amor primeiro: a vida amorosa no imaginário indígena. Id (São Paulo), 34(52), 34-42. Recuperado de http:// pepsic.bvsalud.org/scielo.php?script=sci_arttext\&pi$\mathrm{d}=\mathrm{S} 0101-31062011000100005 \& \operatorname{lng}=\mathrm{pt} \& \mathrm{nrm}=\mathrm{iso}$

Monteiro, J. M. (2001). Tupis, Tapuias e historiadores: estudos de história indígena e do indigienismo. (Tese de livre-docência). Departamento de Antropologia da Universidade de Campinas, Campinas.

Pinheiro, S. L., \& Frota, A. M. M. C. (2009). Uma compreensão da infância dos índios Jenipapo-Kanindé a partir deles mesmos: um olhar fenomenológico, através de narrativas e desenhos. Estudo e Pesquisa em Psicologia, 9(3), 724-759. Recuperado de http:// pepsic.bvsalud.org/scielo.php?script=sci_arttex$\mathrm{t} \& \mathrm{pid}=\mathrm{S} 1808-42812009000300012 \& \operatorname{lng}=\mathrm{pt} \& \mathrm{nrm}=\mathrm{i}-$ so acesso 20-06-2013

Ribeiro, D. (2013). O povo brasileiro: a formação e o sentido do Brasil. São Paulo, SP: Companhia das Letras.

Rosa, E. M., Garcia, M. L. T., \& Leal, F. X. (2007). Derrubam-se as casas: A (des)construção da questão indígena no cenário da política social. Revista Psicologia Politica, 7(14). Recuperado de http:// pepsic.bvsalud.org/scielo.php?script=sci_arttext\&pi$\mathrm{d}=$ S1519-549X2007000200009\&lng=pt\&nrm=iso 
Silva Júnior, G. A. (2000). Educação inclusiva e diferenciada indígena. Psicologia: Ciência e Profissão, 20(1), 40-49. doi:10.1590/S1414-98932000000100006

Vianna, J. J. B., Cedaro, J. J., \& Ott, A. M. T. (2012). Aspectos psicológicos na utilização de bebidas alcoólicas entre os Karitiana. Psicologiae Sociedade, 24(1), 94-103. doi:10.1590/S0102-71822012000100011

Vitale, M. P., \& Grubits, S. (2009). Psicologia e povos indígenas: um estudo preliminar do "estado da arte". Revista Psicologia e Saúde, 1(1), 15-30. Recuperado de http://www.gpec.ucdb.br/pssa/index.php/pssa/ article/view/10

\section{Isabella Tormena Ferraz}

Discente da Universidade Estadual de Maringá, Bolsista PIBIC/CNPQ - FA-UEM, Maringá - PR. Brasil.

E-mail: isabella.tormena@hotmail.com

\section{Eliane Domingues}

Doutora e Docente da Universidade Estadual de Maringá, Maringá - PR. Brasil.

E-mail: elianedomingues3@hotmail.com
Endereço para envio de correspondência:

Rua Rui Barbosa, 456, apto. 704. CEP: 87020-090. Maringá - PR. Brasil.

Recebido: 10/12/2014

$1^{a}$ Reformulação: 21/09/2015

$2^{a}$ Reformulação: 19/12/2015

Aprovado: 29/04/2016

Received: 12/10/2014

$1^{s t}$ Reformulated:09/21/2015

$2^{\text {st }}$ Reformulated: $12 / 19 / 2015$

Approved:04/29/2016

Recibido: 10/12/2014

$1^{\circ}$ Reformulado:21/09/2015

$2^{\circ}$ Reformulado: 19/12/2015

Aceptado: 29/04/2016

Como citar: Ferraz, I. T. \& Domingues, E.(2016). A Psicologia Brasileira e os Povos Indígenas: Atualização do Estado da Arte. Psicologia: Ciência e Profissão, 36(3): 682-695. DOI: 10.1590/1982-3703001622014

How to cite: Ferraz, I. T. \& Domingues, E.(2016). A Brazilian Psychology and the Indigenous Peoples: Updating the State of Art. Psicologia: Ciência e Profissão, 36(3): 682-695. DOI: 10.1590/1982-3703001622014

Cómo citar: Ferraz, I. T. \& Domingues, E.(2016). La Psicología Brasileña y los Pueblos Indígenas: Actualización del Estadio del Arte. Psicologia: Ciência e Profissão, 36(3): 682-695. DOI: 10.1590/1982-3703001622014 